\title{
Environmental risk factors and epigenetic alternations in psoriasis
}

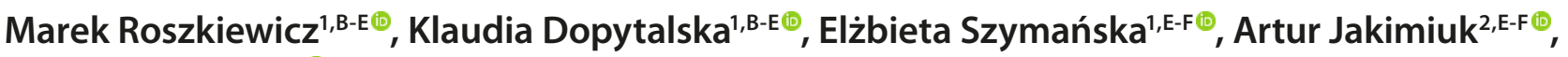 \\ Irena Walecka ${ }^{1, A, E-F}($ \\ ${ }^{1}$ Dermatology Department of Centre of Postgraduate Medical Education, Warsaw, Poland \\ ${ }^{2}$ Center of Reproductive Health, Institute of Mother and Child, Warsaw, Poland Department of Obstetrics and \\ Gynecology CSKMSWiA, Warsaw, Poland \\ $A$ - Research concept and design, B - Collection and/or assembly of data, C - Data analysis and interpretation, \\ $D$ - Writing the article, $E$ - Critical revision of the article, $F$ - Final approval of article
}

Roszkiewicz M, Dopytalska K, Szymańska E, Jakimiuk A, Walecka I. Environmental risk factors and epigenetic alternations in psoriasis. Ann Agric Environ Med. 2020; 27(3): 335-342. doi: 10.26444/aaem/112107

\begin{abstract}
Introduction and objective. Psoriasis isa quite common, chronic and immune-mediated skin disorder. The prevalence of psoriasis differs in various countries, but it is said to affect $2 \%$ of the world's population in general. Psoriasis has many different clinical features but all lesions have the same characteristic: erythema, thickening and scale, although other clinical features are also connected, such as psoriatic arthritis, obesity and metabolic syndrome. All of these may lead to conditions impairing the quality of life. This review is an attempt to summarize recent data regarding environmental factors, together with epigenetic markers and processes playing an important role in psoriasis.

State of knowledge. Many different environmental factors play a role in genetically predisposed patients. This is causes epigenetic alternations which may be a linking part in the whole process. Many studies have indicated a connection between psoriasis and various genes and antigens. The presence of HLA-Cw6 is common as well a strong link between its presence and the onset of psoriasis being observed. The main alternations are DNA methylation, histone's modifications and the role of microRNA. Excessive reaction is usually not present without a triggering factor. Environmental factors are mostly rated, such as drugs, life style and habits (smoking, alcohol), diet, physical trauma (skin injury provoking Koebner phenomenon), stress, microorganism and infections.

Conclusions. The correlation between pathogenesis of psoriasis and environmental risk factors, together with epigenetic alternations still require more investigation. Education about diet habits, nutrition, weight loss and healthy lifestyle seems to be important during the treatment of psoriasis.
\end{abstract}

Key words

psoriasis, habits, environmental factors, epigenetic alternations

\section{INTRODUCTION AND OBJECTIVE}

Psoriasis is a quite common, chronic and immune-mediated skin disorder $[1,2]$. However, environmental factors also play an important role in genetically predisposed patients during the course of the disease. Psoriasis also has many different clinical features and locations, e.g, plaque, guttate, erythrodermic, palmoplantar, nail, and scalp psoriasis [1]. It occurs as sharply demarcated and erythematous papulosquamous lesions. Simultaneously, different manifestations may be seen, but the lesions have the same characteristics: erythema, thickening and scaling. Skin changes are accompanied by intensive itching. Together with psoriasis, other clinical features can also be manifested, such as psoriatic arthritis (PA), obesity and metabolic syndrome, which may lead to impairment of the quality of life (arthritis deformans, ischemic heart disease, heart failure, and stroke) $[3,4,5]$.

The prevalence of psoriasis is higher in well-developed countries compared to those with a low income. It is reported to be even as high as $4.6 \%$ in Canada and the USA, and only $0.4 \%-0.7 \%$ in African and Asian regions. The prevalence

Address for correspondence: Marek Roszkiewicz, Dermatology Department of Centre of Postgraduate Medical Education, Warsaw, Poland

E-mail: marek.roszkiewicz@cskmswia.pl

Received: 06.02.2019; accepted: 03.09.2019; first published: 12.11.2019 is said to be $2 \%$ of the world's population in general [6]. Psoriasis may occur at any age, although two peaks of onset are observed: the first in the second decade of life, and the other in the fifth decade. Almost $75 \%$ of cases begin before the age of 40 . PA is shown to affect $20 \%-30 \%$ of psoriatic patients $[3,7]$.

This review is an attempt to summarize the knowledge on how environmental factors (such as microbiota and infections, diet and obesity, drugs and medications, psychological factors), together with epigenetic markers and processes play an important role in psoriasis development.

\section{STATE OF KNOWLEDGE}

Genes and epigenetics. The genetic predisposition to psoriasis was established many years ago [8], and to-date 424 genes loci with single nucleotide polymorphism have been proven to be associated with psoriasis [9]. However, many studies have shown that these are not the sole critical factors in the pathogenesis of the disease: the role of epigenetic modifications has been emphasized along with environmental factors and lifestyle habits $[2,10]$. According to the widelyknown concept of Lalonde published in 1971, the genetic input in a healthy subject is up to $20 \%$. Almost equal, also up to $20 \%$, are environmental factors, but the majority are 
lifestyle habits that amount to $50 \%$ of psoriasis occurrences. Between those external factors (70\%) and internal ones (20\%), there is a link of epigenetic modifications.

Previous studies have shown a connection between psoriasis and various genes and antigens. Histocompatibility antigens (HLA), situated on the surface of cells and connected with the chromosomal region, the so-called major histocompatibility complex (MHC) also plays an important role. The presence of HLA-Cw6 has been observed at the onset of psoriasis and is seen in $90 \%$ of patients with earlyonset and 50\% with late onset. In a control population, HLACw6 was present in barely 7\% [11, 12]. Another HLA compound connected to psoriasis, and specifically to reactive arthritis or sacroilitis - HLA-B27 - is also seen in other diseases, especially rheumatic $[13,14]$.

Furthermore, there are at least 15 chromosomal regions suspected of being associated with psoriasis, called PSORS1-15, among which HLA-Cw6 is contained [9, 15]. In 2012, Tsoi et. al. identified 15 new psoriasis susceptibility loci by employing meta-analysis of three genome-wide association studies (GWAS) and two other datasets [16]. Establishing those new correlations increased the number of psoriasis associated genes to 36 (Tab. 1), most of which are connected to innate and adaptive immunity and their mutual relations; only a few encode skin-specific proteins. There is a main gene link to interferon (INF), nuclear factor kappa-light-chain-enhancer of activated B cells (NF- $\kappa \mathrm{B})$ signalling, interleukin (IL) 4 and IL-23/17 axis [17, 18, 19].

Table 1. Psoriasis susceptibility genes [16-19]

PSORIASIS SUSCEPTIBILITY GENES

\begin{tabular}{|c|c|}
\hline Character & Pathways and genes \\
\hline \multirow{3}{*}{ Innate immunity } & $\begin{array}{l}\text { NF-KB signaling: CARDI4, CARMI, FBXL19, NFKBIA, REL, } \\
\text { TNFAIP3, TNIP1, UBE2L3 }\end{array}$ \\
\hline & IFN signaling: DDX58, ELMOI, IFIHI, IL-28RA, RNF114 \\
\hline & Inflammation: NOS2 \\
\hline \multirow{5}{*}{ Adaptive immunity } & IL-23/17 axis and IL-17: IL-23R, IRF4, STAT3 \\
\hline & T cell: RUNX3, TNFRSF9, TAGAP \\
\hline & IL-4/13 signaling: IL-4/13 \\
\hline & TGF-beta signaling: ZMIZI \\
\hline & INF signaling: SOCSI \\
\hline \multirow{2}{*}{$\begin{array}{l}\text { Mutual (innate and } \\
\text { adaptive) immunity }\end{array}$} & IL-23/17 axis: IL-12B, IL-23A, TRAF31P3, TYK2 \\
\hline & MHC antigen presentation: ERAPI, HLA-C \\
\hline \multirow{2}{*}{ Skin specific } & Skin barrier: $L C E 3 B / 3 C / 3 D, K L F 4$ \\
\hline & Other: ETSI \\
\hline \multirow{3}{*}{ Other } & Redox signaling: PRDX5 \\
\hline & Carbohydrate metabolism: B3GNT2 \\
\hline & Other: $M B D 2, Z C 3 H 12 C$ \\
\hline
\end{tabular}

Since the last decade, the importance of epigenetic alternations has been studied worldwide to shed more light on understanding the pathological pathway in psoriasis. The main alternations are DNA methylation, histone modifications and the role of microRNA [20]. The influence of epigenetic modifications on the gene expression may be twofold: DNA hypermethylation of the region plays an important role in silencing gene transcription, while hypomethylation in its activation $[21,22]$.
In 2008, Chen et al. indicated a potential role of the p16 gene alternation in psoriasis. They report methylation of p16INK 4 a gene promoter in the epidermis of 30\% of psoriatic patients and correlation with higher Psoriasis Area and Severity Index (PASI) scores [23]. Protein p16INK4a negatively regulates CDK4 and CDK6 proteins, which promotes progression from $\mathrm{G} 1$ to $\mathrm{S}$ phase in the cell growth cycle [24]. Also, the down regulation of p16INK4a due to methylation leads to higher levels of CDK4 and CDK6, which has been identified in different hyperproliferative skin diseases and skin malignancies (e.g. squamous cell carcinoma) [25]. Furthermore, Zhang et al. report decreased levels of programmed cell death 5 protein (PDCD5) and tissue inhibitor of metalloproteinases 2 (TIMP2) in the psoriatic lesions [26]. Methylation of both proteins is associated with keratinocytes proliferation as well as in tumour formation $[27,28]$.

Recent studies by Chandra et al. and Zhao et al. report epigenome-wide DNA methylation as one of the features playing a key role in psoriasis [21, 29]. The study by Chandra revealed a significant difference in the enrichment of methylated CpGs in PSORS regions, where it shows an inverse correlation with higher gene expression [29]. A link between histopathological findings (such as Munro's microabscess, parakeratosis, and neutrophil accumulation) has also been established [29]. Zhao reports that global DNA methylation is significantly increased in peripheral blood mononuclear cells and skin lesions of psoriatic patients compared to healthy controls [21]. Moreover, different pathways of hematopoietic cells and psoriatic lesions have also been indicated, e.g. SHP-1 promoter 2 methylation, although for clear understanding of those compound, further studies are required $[22,30]$.

In the study by Gervin et al., $66 \%$ of the co-occurrence of psoriasis in monozygotic (MZ) twins did not show a significant difference in DNA methylation in CD4+ and CD8+ cells of MZ twins [31]. Analysis of the data showed no difference in methylated or expressed genes between twins when analyzed separately. However, combined analysis of DNA methylation and gene expression identified genes where the differences in DNA methylation between unaffected and affected twins were correlated with differences in gene expression (IL-13, ALOX5AP, PTHLH and TNFSF11) [31, $32,33,34,35]$.

The significance of epigenetic alternations in psoriasis has also been shown in histone $(\mathrm{H})$ modifications. OvejeroBenito et al. report a significant difference in psoriatic patients, presenting reduced levels of acetylated $\mathrm{H} 3$ and $\mathrm{H} 4$, and increased levels of methylated H3K4. Moreover, after introducing biological treatment there were no significant changes in histone modification. Nevertheless, a significant difference in H3K27 alternations was found between responders and non-responders to the biological agent after three months of treatment [36].

Another candidate for playing a significant role in the course of psoriasis may be microRNA (miRNA), and recent studies have provided new insight regarding miRNA importance in the disease. Some studies reported an overexpression of many types of miRNA play a triggering or exaggerating role (e.g. miRNA-21, -31, -146), but on the other hand, others revealed downregulation of miRNA (e.g. miRNA-145-5p, -197) in patients with active psoriasis [37, $38,39]$. A recent study by Wu et al. showed new miRNA in psoriasis, which happens to be one of the most investigated 
miRNA's to-date - miRNA-210 [40]. The study compared the expression of miRNA-210 in psoriatic patients and mice models (imiquimod or interleukin (IL) 23 induced psoriaticlike lesions). $\mathrm{Wu}$ reports significantly increased levels of miRNA-210 in CD4+ T cells in both psoriasis patients and mice models in the dermis as well as the epidermis. Moreover, miRNA-210 promotes Th1 and Th17 activation increasing IL-17 levels while lowering IL-4. This leads to an imbalance in T cell population (Th1/Th2 and Th17/Treg) [41]. Th2 cell differentiation was also inhibited by repressing the signal transducer and the activator of transcription 6 (STAT6) and tyrosine-protein kinase Lyn (LYN) genes expression. Mice models were also transfected with oligonucleotides that induce miRNA overexpression or silencing [42]. A further study shows that TGF-beta and IL-23 enhance overexpression of miRNA-210 by histone $\mathrm{H} 3$ acetylation in the miRNA-210 region. Finally, inducing psoriasis-like lesions in mice models was blocked when the miRNA-210 region was deleted or inhibited [40]. As indicated above, new compound targeting miRNA-210 may play an important role in future therapeutic investigations in psoriasis.

All these factors, genetic predisposition merged with epigenetic modification caused by strong environmental factors, influenced results in immune system activation [10]. Antigen-presenting cells and different T cell's populations (e.g. Th17 helper cells) and their relation to HLA play a key role in the psoriasis pathogenic pathway by recruiting other CD8+T-cells CD8+ as well as natural killers (NK) [43]. Activated cells produce a vast number of pro-inflammatory cyto- and chemokines (such as interleukins, interferons INF, etc.). The connection between psoriasis and at least IL-4, 17, 23 has been established [44, 45, 46]. Those are also a grip point for modern, biological treatment options, which inhibit the exaggerated immune reaction which is usually not present without a triggering factor. Such factors are mostly environmental and are related, among others, to drugs, lifestyle habits (smoking, alcohol), diet, physical trauma (skin injury provoking Koebner phenomenon), stress, microorganisms and infections $[10,47,48]$.

Microbiota and infections. Recently, great attention has been paid to the role of microbiota in different diseases, especially in autoimmune or immune-mediated conditions. Among a vast number of such diseases, the most emminent is inflammatory bowel disease (IBD) - Crohn's disease (CD) [49, 50, 51]. The CD patient is at a higher risk of developing psoriasis than that of the general population. Vice versa, a psoriatic patient is more likely to suffer from CD [52]. In a healthy human subject, there is a mutual coexistence of different microorganisms (viruses, bacteria, and fungi) within the skin, mucous membranes (intestines, upper airways, urogenital tract), which constitutes an immunological balance with immune system cells [53]. Any disruption of this microenvironment may occur or provoke either infection by the domination of one kind of microorganism, or activation of the immune system. Many of the microorganisms' molecules can be a triggering antigen for immune reaction. Due to the similarity of different proteins and other compounds of the bacterial wall to human substances, a reaction may occur leading to an auto-aggressive process $[54,55]$. Such reactions run through two kinds of pathways: innate and adaptive immune system response. The innate pathway is usually quick whereas the other takes time to develop, but creates a
Table 2. Microbiota and psoriasis $[10,51,64]$

\begin{tabular}{ll}
\hline MICROBIOTA & \\
\hline Localization & Species \\
\hline Tonsils & Streptococcus spp. \\
\hline \multirow{3}{*}{ Skin } & Streptococcus spp. \\
& Staphylococcus spp. \\
& Candida spp. \\
& Malassezia spp. \\
Gut & Propionibacterium acnes* \\
\hline
\end{tabular}

* rarely present on skin of psoriatic patients

kind of immune memory using a special subtype of T cells. In psoriatic patients, the adaptive immune response plays a vital role because of the high sensitization of T cells (especially Th17 cells) due to exposure to microorganism antigens [19].

It has been shown that during the life span of the human, the microbiome is relatively stable [56]. An unhealthy lifestyle (e.g. tobacco, alcohol intake or diet) as well as stress affects this homeostatic microenvironment [57]. Especially diet and the quality of food play an important role. Due to the usage of hormones and antibiotics in animal breeding, but also due to the industrialization of agriculture, in general, diet can be an additional risk factor disturbing proper relations in such a micro-ecosystem [58]. It has been indicated that the skin of a psoriatic patient has different microbiome than a control group. Staphylococcus and Streptococcus are most commonly seen, even in all layers of the skin $[10,59]$. Moreover Malassezia and Candida species are also connected to psoriasis [10]. On the contrary, Propionibacterium acnes is usually present on a healthy individual's skin rather than the psoriatic [59]. Because of this, as mentioned above, such a disturbance in microbiota's relations provokes immune reaction, conducted especially by IL-22 producing T cells which play a critical role in the aggravation of skin inflammation $[10,60]$.

Furthermore, the role of gastrointestinal microbiota has not been finally established. Multiple studies indicated an intestinal inflammation during the course of PA $[61,62,63]$. An evident relation is between psoriasis and IBD [52], for example, Bacteroides fragilis or Clostridium species promote Treg cells differentiation [64]. Another infectious factor is Sptreprococcus in the tonsils. It is commonly known, that many upper airway tract infections may intensify psoriatic lesions $[65,66,67]$.

Recently, a hypothesis of the gut-brain-skin axis is being developed [68]. It has been proved that various skin disorders (urticarial, atopic dermatitis, psoriasis) have a strong correlation with the emotional status of the patient $[69,70,71,72]$. It has been shown that there is a negative influence on the immune system causing a greater risk of infections in patients subjected to mild to severe chronic stress [72]. Impairing work of the immune system occurs as an imbalance between the mutual microenvironment of microbiota and immune cells, which allows pathogens to extend and lead to infection [73]. On the other hand, this stimulates the immune system's reaction and usually occurs as an exacerbation, or even provokes the onset of psoriasis $[65,66,67]$.

Diet and obesity. Among the environmental risk factors for psoriasis, body weight and nutritional habits are considered 
to be very crucial in the pathogenesis of the disease, and can trigger or exacerbate the symptoms. It is known that obesity, increased body mass index (BMI) and waist circumference are significant risk factors for the development of psoriasis $[10,74,75,76,77]$. Furthermore, the prevalence of obesity and metabolic syndrome is higher in psoriatic patients than in the general population - it is estimated, that around 50\% of psoriatic patients are overweight or obese. This may lead to increased cardiovascular risks. Moreover, the severity of psoriasis (evaluated by the Psoriasis Area and Severity Index - PASI) is higher in obese or overweight patients [78, 79, 80].

Obesity is known as a low-grade chronic inflammatory process with elevated levels of C-reactive protein, Il-6, TNFand leptin. According to recent studies, a pathogenetic link between obesity and psoriasis could be an inflammatorytype involving macrophages, pro-inflammatory adipokines, and cytokines. The role of adipokines in psoriasis has been the aim of many recent studies $[75,81,82]$. Leptin is an adipokine, the main function of which is to regulate food intake. Besides, leptin has an immunomodulatory effect by stimulating macrophages to produce pro-inflammatory cytokines (TNF- $\alpha$, IL-6) and may induce the proliferation of Th1 cells $[83,84]$. Recent data has shown that psoriatic patients have elevated serum leptin levels, compared to the healthy population. Psoriasis is also considered to be a risk factor of hyperleptinaemia $[85,86]$. Furthermore, in psoriasis, the serum level of adiponectin (anti-inflammatory adipocine) is decreased and inversely correlates with the extent of psoriasis symptoms. Not only adipokine is linked between psoriasis and obesity, but also TNF- $\alpha$. It has been shown that excessive production of the tumour necrosis factor plays an important role in the pathogenesis of psoriasis and leads to a rapid proliferation of skin cells. There is evidence, that TNF-a may also influence the severity of psoriatic lesions in obese patients because of the overexpression of the TNF- $\alpha$ in adipose tissue $[75,87]$.

Obesity also influences the treatment of psoriasis by affecting both the drug's pharmacokinetics and pharmacodynamics. Obese patients with psoriasis often have a decreased response to systemic and biological therapy. This is observed especially with drugs that are administered in fixed doses rather than in those where the dose is adjusted to the patient's weight. Treatment with biological drugs in which the dose is not weight-adjusted (e.g. adalimumab, etanercept) may have worse efficiency, whereas the cost of therapy with weightadjusted biological drugs (e.g ustekinumab, infliksimab) is higher. Also, obesity is often associated with metabolic or hepatic disorders, which raise the risk of adverse effects to conventional systemic therapy $[75,81,88]$. Recent data have shown that in obese patients during biological treatment with an eight week low-calorie diet (under 1,000 kcal/day), the weight reduction was associated with increased efficacy of the biologic drug [89].

Other reports underline cases of patients who had undergo gastric bypass surgery for other indications, had an improvement in the course of psoriasis [90]. Changing the lifestyle, especially losing weight, may due to the reduction of the obesity-related inflammation, improved effectiveness of therapy and decrease in the side-effects of conventional therapy.

The benefits of reduction in body weight in psoriasis are significant in both the severity of disease and the response to treatment. Diet and nutritional supplements may also have benefits in psoriatic patients; evidence has been provided that diets rich in omega-3 polyunsaturated fatty acids (omega-3 PUFA) from fish oil have been associated with the improvement of psoriasis in clinical trials, mostly by exhibiting an anti-inflammatory effect $[91,92]$. In some patients, particularly those with gluten intolerance, a glutenfree diet might be beneficial. Epidemiological and clinical data suggest that there could be a correlation between psoriasis, celiac disease and celiac disease markers, but further research into this matter is necessary [93].

There is some evidence that supplementation with selenium and vitamin B12 might have a positive influence on psoriasis symptoms [94]. It is also believed, that other vitamins (A, $\mathrm{E}, \mathrm{C}$ ) and microelements (iron, manganese, zinc) decrease oxidative stress and the production of reactive oxygen species, which play a role in inflammation [94]. Research has proved that in the patients with psoriasis and coexisting vitamin D insufficiency, oral vitamin D supplementation may have its benefits [92].

The traditional Mediterranean diet, composed of vegetables, fruits, nuts, cereals and fish, is considered a healthy eating pattern associated with reduced risk for metabolic, cardiovascular, neoplastic and chronic inflammatory diseases $[75,95,96,97]$. High contents of antioxidants and polyphenols in the Mediterranean diet have anti-inflammatory and antioxidant properties, which are considered to be protective against chronic inflammatory diseases and may also provide benefits for psoriatic patients [75].

Smoking and alcohol intake. Most data have shown that smoking and exposure to second hand smoke are independent risk factors in psoriasis. Smoking is also often associated with an increased risk of cardiovascular diseases. Moreover, in the group of patients with psoriasis, an increased prevalence of smoking has been observed. They also continue to smoke more cigarettes than patients without psoriasis [74, 98].

Many pathophysiological mechanisms link smoking to psoriasis [99]. Smoking leads to oxidative stress, reduces the number of antioxidants and may increase vascular endothelial dysfunction and plasma viscosity [98, 100]. Increased exposure to free radicals, which are components of cigarette smoke, may trigger a cascade of systemic disorders, including developments of psoriasis [83]. Nicotine, through nicotineactivating pathways, can increase the secretion of cytokines, such as IL-12, IL-2, TNF, INF- $\alpha$, and the granulocyte monocyte colony-stimulating factor [101]. Cigarette smoking may cause disregulation of vascular endothelial growth factor and the processes of angiogenesis. This pathomechanism may partly explain the correlation between smoking, psoriasis, and atherosclerosis $[98,101]$. Furthermore, according to a study on the relationship between smoking and the severity of psoriasis, higher PASI scores were observed in patients with psoriasis who were smokers, compared to non-smoking patients [102]. Additionally, research by Hojgaard et. al. showed, that heavy smoking could decrease the effectiveness of treatment with TNF- $\alpha$ inhibitors [103].

The correlation between alcohol consumption and risk of psoriasis is still unclear and many studies have drawn conflicting conclusions. It is known that alcohol intake may increase the production of pro-inflammatory cytokines, promoting lymphocytes proliferation, which can trigger chronic systemic inflammation. Studies have shown, that alcohol and acetone can stimulate keratinocyte proliferation, 
raise the mRNA levels of genes characteristic of proliferating keratinocytes (a5 integrin, cyclin D1, keratinocytes growth factor receptor) $[98,104]$.

The correlations between smoking or alcohol intake and psoriasis still require further investigation and understanding the pathomechanism, as well as their influence on the severity of symptoms in psoriasis and impact on treatment.

UV in psoriasis. The spectrum of ultraviolet radiation is divided due to the wavelengths int: the short band UVC $(100-290 \mathrm{~nm})$ - which is mostly absorbed by the ozone layer in the atmosphere, the medium band UVB (290-320), and the long band UVA (320-400 nm). The improvement of psoriatic skin lesions after exposure to sunlight or artificial UV sources has been observed for a long time. Psoralen-UVA (PUVA combined therapy of taking oral Psoralen with exposure to UVA) and narrowband UVB (311 $\mathrm{nm}+/-2)$ - are widely used in the treatment of psoriasis [105].

Phototherapy is also considered to be an effective and relatively safe therapeutic option. The positive impact of phototherapy in the management of psoriasis is related to a few mechanisms. UVB stimulates the synthesis of vitamin $\mathrm{D}(25[\mathrm{OH}] \mathrm{D})$, which has been proven to play a role in the treatment of psoriasis due to the regulation of dendritic cells. Moreover, the benefits of UVB include its pro-apoptotic effect and induction of pro- and anti-inflammatory cytokines production. It has been observed that UV suppresses the differentiation of Th17 and downregulates IL-23/IL-17 expression and psoriasis-related antimicrobial peptides (AMPs). Furthermore, phototherapy leads to a decrease in the immune cells migration to the skin, which results in a reduction of the inflammatory processes in psoriasis $[106,107]$.

Although UV exposure is most often beneficial in psoriasis, in some cases, however, the aggravation of psoriasis has been observed. The pathomechanisms of the worsening of the symptoms of psoriasis after UV exposure is not fully understood - the reason for this phenomenon include Koebner reaction after sunburn (as skin trauma) or coexistence of other photosensitivity disorders. Furthermore, there is a subset of patients with psoriasis in whom UV exposure can trigger the disease and induce plaques de novo. This has been described as severely photosensitive psoriasis (PP) with the tendency to seasonal exacerbations of the disease [108]. PP has similar features to polymorphic light eruption (PLE), and in approximately $40 \%$ of cases it can be associated with PLE $[107,109]$.

Medications. There is evidence that some drugs may initiate psoriasis de novo, exacerbate pre-existing psoriasis lesions, and induce a treatment-resistant form of psoriasis. In the optimal management of psoriasis, it is essential to identify these medications, but in everyday clinical practice this it could be particularly difficult. The manifestations of drugrelated psoriasis are varied, from plaque-type psoriasis to severe erythroderma. There are a few mechanisms of drug-related psoriasis. First, drugs exacerbate pre-existing skin lesions. In drug-induced psoriasis, improvement of the disease is observed after discontinuation of the suspected drug. On the other hand, in drug-aggravated psoriasis, the induced psoriatic skin lesions could last even after withdrawal of the drug. Second, drugs may lead to the onset of new psoriasis in patients with or without a personal or family history of the disease [110]. Traditionally, drugs that are proven to be associated with the induction or exacerbation of psoriasis include beta-blockers, antivirals and antidepressants, lithium, synthetic antimalarials (chloroquine and hydroxychloroquine), non-steroidal antiinflammatory drugs (NSAIDs), interferons and terbinafine $[111,112]$. Moreover, quick discontinuation of systemic corticosteroids or high-potency topical corticosteroids can cause a rebound effect and induce the worsening of psoriasis [113].

Recently, new drugs have been reported to induce or exacerbate symptoms of psoriasis, and include monoclonal antibody- and small-molecule-based targeted therapies used for oncological and immunological indications, (TNF- $\alpha$ ) antagonists, nivolumab and pembrolizumab (anti-programmed cell death protein 1 immune checkpoint inhibitors), bupropion (nicotine receptor antagonist), vascular endothelial growth factor (VEGF) antagonists and rituximab (anti-CD20) [105]. One hypothesis suggests an interaction between TNF- $\alpha$ and INF- $\alpha$ (cytokine, which controls natural immunity), where TNF- $\alpha$ inhibits INF- $\alpha$ production. Anti-TNF biologic therapy may boost INF- $\alpha$ production and promote psoriasis [114].

Psychological factors. Psoriasis has a significant influence on the quality of life. The appearance of skin lesions in psoriasis may lead to mental disorders: which most often include sleep disorders, sexual dysfunction, personality disorders, anxiety disorders, adjustment and depressive disorders. The prevalence of depression in psoriatic patients is estimated to range from $10-62 \%$, depending on different studies. On the other hand, stress and depression may have a role in the development and aggravation of the symptoms in psoriasis. This leads to a vicious circle, which worsens both diseases psoriasis and depression $[115,116,117]$. Psychological stress is related to changes in the regulation of the immune system and the activation of abnormal $\mathrm{T}$ cells, which influence psoriasis [116]. Furthermore, psoriatic patients have a higher risk of manifesting psychopathological symptoms during childhood and adolescence. The disease could be also associated with personality alterations [118]. Data has shown that in psoriatic patients complying, self-motivation and self-drive are low, and they can be dependent, submissive, and often lack initiative or do not have opinions of their own. Overall, psoriasis is related to a lower satisfaction with life $[119,120]$.

\section{CONCLUSIONS}

Correlation between environmental risk factors, epigenetic alternations, gene expression, and psoriasis has been investigated in many studies. Most data have shown that obesity and nutritional habits have significant roles in the pathogenesis of the disease, can trigger or exacerbate the symptoms of psoriasis, and have an impact on the effectiveness of the therapy. Also, some medications (betablockers, lithium, synthetic antimalarials, non-steroidal anti-inflammatory drugs) may be triggering factors in psoriasis. Psychological disorders, such as depression, could also aggravate skin lesions. It is also worth noting that changes in microflora and prolonged infections are considered to be risk factors in the development of psoriasis. 
Moreover, maintaining regular, healthy microbiota on the skin or within the gastric tract is very dependent on a healthy diet and lifestyle habits. As shown by reported data, gene predisposition with environmental factors are intermediated by epigenetic alternations. Those three domains together play an important part in the formation of the disease; however, environmental factors (using Lalonde's concept) are mostly responsible for the occurrence of diseases such as psoriasis. The correlation between the pathogenesis of psoriasis and environmental risk factors, as well as the influence on gene expression by epigenetic modifications, require further investigation. Education about proper diet habits, nutrition, weight loss, and a healthy lifestyle, as well as an emphasis on the crucial role of those factors in the pathogenesis of the disease, cannot be overestimated during the treatment as they influence the occurrence, severity, and progression of psoriasis.

\section{REFERENCES}

1. van de Kerkhof PCM, Nestle FO. Psoriasis. In: Bolognia J, Schaffer JV, Cerroni L, editors. Dermatology. Fourth Edition, Elsevier 2017; p. $135-156$.

2. Nestle FO, Kaplan DH, Barker J. Psoriasis. N Engl J Med. 2009 Jul 30; 361(5): 496-509.

3. Galezowski A, Maccari F, Hadj-Rabia S, Sigal ML, Phan A, Lahfa M Psoriatic arthritis in France, from infants to the elderly: Findings from two cross-sectional, multicenter studies. Ann Dermatol Venereol. 2017 Nov 13. pii: S0151-9638(17)30968-7.

4. El-Boghdady NA, Ismail MF, Abd-Alhameed MF, Ahmed AS, Ahmed $\mathrm{HH}$ Bidirectional Association Between Psoriasis and Obesity: Benefits and Risks. J Interferon Cytokine Res. 2017 Dec 18.

5. Ansarimoghaddam A, Adineh HA, Zareban I, Iranpour S, HosseinZadeh A, Kh F. Prevalence of metabolic syndrome in MiddleEast countries: Meta-analysis of cross-sectional studies. Diabetes Metab Syndr. 2017 Dec 2. pii: S1871-4021(17)30350-8.

6. Lebwohl MG, Bachelez H, Barker J, Girolomoni G, Kavanaugh A, Langley RG, et al. Patient perspectives in the management of psoriasis: results from the population-based Multinational Assessment of Psoriasis and Psoriatic Arthritis Survey. J Am Acad Dermatol. 2014 May; 70(5): 871-81.e1-30.

7. Tillett W, Charlton R, Nightingale A, Snowball J, Green A, Smith $\mathrm{C}$, et al. Interval between onset of psoriasis and psoriatic arthritis comparing the UK Clinical Practice Research Datalink with a hospitalbased cohort. Rheumatology (Oxford). 2017 Dec 1; 56(12): 2109-2113.

8. Russell TJ, Schultes LM, Kuban DJ. Histocompatibility (HL-A) antigens associated with psoriasis. N Engl J Med. 1972 Oct 12; 287(15): 738-40.

9. Singh S, Pradhan D, Puri P, Ramesh V, Aggarwal S, Nayek A, et al. Genomic alterations driving psoriasis pathogenesis. Gene. 2019 Jan 30; 683: 61-71. doi: 10.1016/j.gene.2018.09.042. Epub 2018 Oct 1.

10. Zeng J, Luo S, Huang Y, Lu Q. Critical role of environmental factors in the pathogenesis of psoriasis. J Dermatol. 2017 Aug; 44(8): 863-872. doi: 10.1111/1346-8138.13806. Epub 2017 Mar 27.

11. Schmitt-Egenolf M, Eiermann TH, Boehncke WH, Ständer M, Sterry W. Familial juvenile onset psoriasis is associated with the human leukocyte antigen (HLA) class I side of the extended haplotype Cw6B57-DRB1 ${ }^{\star} 0701-D Q A 1{ }^{*} 0201-D Q B 1{ }^{*} 0303$ : a population- and familybased study. J Invest Dermatol. 1996 Apr; 106(4): 711-4.

12. Chen L, Tsai TF. HLA-Cw6 and psoriasis. Br J Dermatol. 2017 Oct 26.

13. Sönmez HE, Batu ED, Demir S, Bilginer Y, Özen S. Comparison of patients with familial Mediterranean fever accompanied with sacroiliitis and patients with juvenile spondyloarthropathy. Clin Exp Rheumatol. 2017 Nov-Dec; 35 Suppl 108(6): 124-127.

14. Dashti N, Javadi Z, Safari F, Farahvash S, Zarebavani M. Estimation of Diagnostic Markers in Rheumatoid Arthritis and Ankylosing Spondylitis. Clin Lab. 2017 Apr 1; 63(4): 797-800.

15. Pasić A, Lipozencić J, Ceović R, Kostović K. The genetics of psoriasis-selected novelties in 2008. Acta Dermatovenerol Croat. 2009; 17(3): 176-81.

16. Tsoi LC, Spain SL, Knight J, Ellinghaus E, Stuart PE, Capon Fm et al. Identification of 15 new psoriasis susceptibility loci highlights the role of innate immunity. Nat Genet. 2012 Dec; 44(12): 1341-8. doi: 10.1038/ ng.2467. Epub 2012 Nov 11.

17. Strange A, Capon F, Spencer CC, Knight J, Weale ME, Allen MH et al. A genome-wide association study identifies new psoriasis susceptibility loci and an interaction between HLA-C and ERAP1. Nat Genet. 2010 Nov; 42(11): 985-90. doi: 10.1038/ng.694. Epub 2010 Oct 17.

18. Capon F, Di Meglio P, Szaub J, Prescott NJ, Dunster C, Baumber L, et al. Sequence variants in the genes for the interleukin-23 receptor (IL23R) and its ligand (IL12B) confer protection against psoriasis. Hum Genet. 2007 Sep; 122(2): 201-6. Epub 2007 Jun 22.

19. Di Cesare A, Di Meglio P, Nestle FO. The IL-23/Th17 axis in the immunopathogenesis of psoriasis. J Invest Dermatol. 2009 Jun; 129(6): 1339-50.

20. Trowbridge RM, Pittelkow MR. Epigenetics in the pathogenesis and pathophysiology of psoriasis vulgaris J Drugs Dermatol. 2014 Feb; 13(2): 111-8.

21. Zhao M1, Lu Q. The Aberrant Epigenetic Modifications in the Pathogenesis of Psoriasis. J Investig Dermatol Symp Proc. 2018 Dec; 19(2): S81-S82. doi: 10.1016/j.jisp.2018.09.007.

22. Li Y, Sawalha AH, Lu Q. Aberrant DNA methylation in skin diseases. J Dermatol Sci. 2009 Jun; 54(3): 143-9. doi: 10.1016/j. jdermsci.2009.01.009. Epub 2009 Apr 22.

23. Chen M, Chen ZQ, Cui PG, Yao X, Li YM, Li AS, et al. The methylation pattern of pl6INK4a gene promoter in psoriatic epidermis and its clinical significance. Br J Dermatol. 2008 May; 158(5): 987-93. doi: 10.1111/j.1365-2133.2008.08505.x. Epub 2008 Mar 28.

24. Serrano M, Hannon GJ, Beach D. A new regulatory motif in cell-cycle control causing specific inhibition of cyclin D/CDK4. Nature. 1993 Dec 16; 366(6456): 704-7.

25. Brown VL, Harwood CA, Crook T, Cronin JG, Kelsell DP, Proby CM. p16INK4a and p14ARF tumor suppressor genes are commonly inactivated in cutaneous squamous cell carcinoma. J Invest Dermatol. 2004 May; 122(5): 1284-92.

26. Zhang P, Zhao M, Liang G, Yin G, Huang D, Su F, et al. Whole-genome DNA methylation in skin lesions from patients with psoriasis vulgaris. J Autoimmun. 2013 Mar; 41: 17-24. doi: 10.1016/j.jaut.2013.01.001. Epub 2013 Jan 29.

27. Spinola M, Meyer P, Kammerer S, Falvella FS, Boettger MB, Hoyal $\mathrm{CR}$, et al. Association of the PDCD5 locus with lung cancer risk and prognosis in smokers. J Clin Oncol. 2006 Apr 10; 24(11): 1672-8. Epub 2006 Mar 20.

28. Su DM, Zhang Q, Wang X, He P, Zhu YJ, Zhao J, et al. Two types of human malignant melanoma cell lines revealed by expression patterns of mitochondrial and survival-apoptosis genes: implications for malignant melanoma therapy. Mol Cancer Ther. 2009 May; 8(5): 1292-304. doi: 10.1158/1535-7163.MCT-08-1030. Epub 2009 Apr 21.

29. Chandra A, Senapati S, Roy S, Chatterjee G, Chatterjee. Epigenomewide DNA methylation regulates cardinal pathological features of psoriasis. Clin Epigenetics. 2018 Aug 9; 10(1): 108. doi: 10.1186/s13148018-0541-9.

30. Ruchusatsawat K, Wongpiyabovorn J, Shuangshoti S, Hirankarn N, Mutirangura A. SHP-1 promoter 2 methylation in normal epithelial tissues and demethylation in psoriasis. J Mol Med (Berl). 2006 Feb; 84(2): 175-82. Epub 2005 Dec 31.

31. Gervin K, Vigeland MD, Mattingsdal M, Hammerø M, Nygård H, Olsen AO, et al. DNA methylation and gene expression changes in monozygotic twins discordant for psoriasis: identification of epigenetically dysregulated genes. PLoS Genet. 2012 Jan; 8(1): e1002454. doi: 10.1371/journal.pgen.1002454. Epub 2012 Jan 19.

32. Nair RP, Duffin KC, Helms C, Ding J, Stuart PE, Goldgar D, et al. Genome-wide scan reveals association of psoriasis with IL-23 and NFkappaB pathways. Nat Genet. 2009 Feb; 41(2): 199-204. doi: 10.1038/ ng.311. Epub 2009 Jan 25.

33. Dixon RA, Diehl RE, Opas E, Rands E, Vickers PJ, Evans JF, et al. Requirement of a 5-lipoxygenase-activating protein for leukotriene synthesis. Nature. 1990 Jan 18; 343(6255): 282-4.

34. Taylor JM, Street TL, Hao L, Copley R, Taylor MS, Hayden PJ, et al. Dynamic and physical clustering of gene expression during epidermal barrier formation in differentiating keratinocytes. PLoS One. 2009 Oct 30; 4(10): e7651. doi: 10.1371/journal.pone.0007651.

35. Holick MF, Chimeh FN, Ray S. Topical PTH (1-34) is a novel, safe and effective treatment for psoriasis: a randomized self-controlled trial and an open trial. Br J Dermatol. 2003 Aug; 149(2): 370-6.

36. Ovejero-Benito MC, Reolid A, Sánchez-Jiménez P, Saiz-Rodríguez M, Muñoz-Aceituno E, Llamas-Velasco M, et al. Histone modifications associated with biological drug response in moderate-to-severe 
psoriasis. Exp Dermatol. 2018 Dec; 27(12): 1361-1371. doi: 10.1111/ exd.13790.

37. Yan JJ, Qiao M, Li RH, Zhao XT, Wang XY, Sun Q. Downregulation of miR-145-5p contributes to hyperproliferation of keratinocytes and skin inflammation in psoriasis. Br J Dermatol. 2018 Sep 30. doi: 10.1111/bjd.17256. [Epub ahead of print]

38. Timis TL, Orasan RI. Understanding psoriasis: Role of miRNAs. Biomed Rep. 2018 Nov; 9(5):367-374. doi: 10.3892/br.2018.1146. Epub 2018 Sep 11.

39. Wcisło-Dziadecka D, Simka K, Kaźmierczak A, Kruszniewska-Rajs C, Gola J, Grabarek B, et al. Psoriasis Treatment Changes the Expression Profile of Selected Caspases and their Regulatory MicroRNAs. Cell Physiol Biochem. 2018; 50(2): 525-537. doi: 10.1159/000494166. Epub 2018 Oct 11.

40. Wu R, Zeng J, Yuan J, Deng X, Huang Y, Chen L, et al. MicroRNA-210 overexpression promotes psoriasis-like inflammation by inducing Th1 and Th17 cell differentiation. J Clin Invest. 2018 Jun 1; 128(6): 2551-2568. doi: 10.1172/JCI97426. Epub 2018 May 14.

41. Diani M, Altomare G, Reali E. T Helper Cell Subsets in Clinical Manifestations of Psoriasis. J Immunol Res. 2016; 2016: 7692024. doi: 10.1155/2016/7692024. Epub 2016 Aug 10.

42. Krützfeldt J, Rajewsky N, Braich R, Rajeev KG, Tuschl T, Manoharan $\mathrm{M}$, et al. Silencing of microRNAs in vivo with 'antagomirs'. Nature. 2005 Dec 1; 438(7068): 685-9. Epub 2005 Oct 30.

43. Furuhashi T, Saito C, Torii K, Nishida E, Yamazaki S, Morita A. Photo(chemo)therapy reduces circulating Th17 cells and restores circulating regulatory $\mathrm{T}$ cells in psoriasis. PLoS One. 2013; 8(1): e54895.

44. Di Meglio P, Nestle FO. The role of IL-23 in the immunopathogenesis of psoriasis. F1000 Biol Rep. 2010 May 24; 2. pii: 40.

45. Girolomoni G, Strohal R, Puig L, Bachelez H, Barker J, Boehncke $\mathrm{WH}$, et al. The role of IL-23 and the IL-23/TH 17 immune axis in the pathogenesis and treatment of psoriasis. J Eur Acad Dermatol Venereol. 2017 Oct; 31(10): 1616-1626.

46. Couderc E, Morel F, Levillain P, Buffière-Morgado A1, Camus M1, Paquier C, et al. Interleukin-17A-induced production of acute serum amyloid A by keratinocytes contributes to psoriasis pathogenesis. PLoS One. 2017 Jul 14; 12(7): e0181486.

47. Naldi L, Chatenoud L, Linder D, Belloni Fortina A, Peserico A, Virgili AR, et al. Cigarette smoking, body mass index, and stressful life events as risk factors for psoriasis: results from an Italian case-control study. J Invest Dermatol. 2005 Jul; 125(1): 61-7.

48. Rachakonda TD, Dhillon JS, Florek AG, Armstrong AW. Effect of tonsillectomy on psoriasis: a systematic review. J Am Acad Dermatol. 2015 Feb; 72(2): 261-75.

49. Gomes-Neto JC, Kittana H, Mantz S, Segura Munoz RR, Schmaltz RJ, Bindels LB, et al. A gut pathobiont synergizes with the microbiota to instigate inflammatory disease marked by immunoreactivity against other symbionts but not itself. Sci Rep. 2017 Dec 18; 7(1): 17707.

50. Wang Y, Gao X, Ghozlane A, Hu H, Li X, Xiao Y, et al. Characteristics of Fecal Microbiota in Pediatric Crohn's Disease and Their Dynamic Changes During Infliximab Therapy. J Crohns Colitis. 2017 Nov 29.

51. Rasmussen HE, Hamaker BR. Prebiotics and Inflammatory Bowel Disease. Gastroenterol Clin North Am. 2017 Dec; 46(4): 783-795.

52. Halling ML, Kjeldsen J, Knudsen T, Nielsen J, Hansen LK. Patients with inflammatory bowel disease have increased risk of autoimmune and inflammatory diseases. World J Gastroenterol. 2017 Sep 7; 23(33): 6137-6146.

53. Prescott SL, Larcombe DL, Logan AC, West C, Burks W, Caraballo L, et al. The skin microbiome: impact of modern environments on skin ecology, barrier integrity, and systemic immune programming. World Allergy Organ J. 2017 Aug 22; 10(1): 29.

54. Manasson J, Shen N, Garcia Ferrer HR, Ubeda C, Iraheta I, Heguy A et al. Gut Microbiota Perturbations in Reactive Arthritis and PostInfectious Spondyloarthritis. Arthritis Rheumatol. 2017 Oct 26.

55. Shir A, Klein S, Sagiv-Barfi I, Geiger T, Zigler M, Langut Y, et al. S101, an inhibitor of proliferating T-cells, rescues mice from superantigeninduced shock. J Infect Dis. 2017 Nov 15.

56. Ottman N, Smidt H, de Vos WM, Belzer C. The function of our microbiota: who is out there and what do they do? Front Cell Infect Microbiol. 2012 Aug 9; 2: 104

57. Capurso G, Lahner E. The interaction between smoking, alcohol and the gut microbiome. Best Pract Res Clin Gastroenterol. 2017 Oct; 31(5): 579-588.

58. Landers TF, Cohen B, Wittum TE, Larson EL. A Review of Antibiotic Use in Food Animals: Perspective, Policy, and Potential Public Health Rep. 2012 Jan-Feb; 127(1): 4-22.
59. Nakatsuji T, Chiang HI, Jiang SB, Nagarajan H, Zengler K, Gallo RL. The microbiome extends to subepidermal compartments of normal skin. Nat Commun. 2013; 4: 1431.

60. Zanvit P, Konkel JE, Jiao X, Kasagi S, Zhang D, Wu R, et al. Antibiotics in neonatal life increase murine susceptibility to experimental psoriasis. Nat Commun. 2015 Sep 29; 6: 8424.

61. Rosenbaum IT, Asquith MJ. The Microbiome: a Revolution in Treatment for Rheumatic Diseases? Curr Rheumatol Rep. 2016 Oct; 18(10): 62 .

62. Breban M. Gut microbiota and inflammatory joint diseases. Joint Bone Spine. 2016 Dec; 83(6): 645-649.

63. Scarpa R, Manguso F, D'Arienzo A, D'Armiento FP, Astarita C, Mazzacca G, et al. Microscopic inflammatory changes in colon of patients with both active psoriasis and psoriatic arthritis without bowel symptoms. J Rheumatol. 2000 May; 27(5): 1241-6.

64. Telesford KM, Yan W, Ochoa-Reparaz J, Pant A, Kircher C, Christy MA, et al. A commensal symbiotic factor derived from Bacteroides fragilis promotes human CD39(+)Foxp3(+) T cells and Treg function. Gut Microbes. 2015 Jul 4; 6(4): 234-42.

65. Thorleifsdottir RH, Sigurdardottir SL, Sigurgeirsson B, Olafsson JH, Petersen H, Sigurdsson MI, et al. HLA-Cw6 homozygosity in plaque psoriasis is associated with streptococcal throat infections and pronounced improvement after tonsillectomy: A prospective case series. J Am Acad Dermatol. 2016 Nov; 75(5): 889-896.

66. Ruiz-Romeu E, Ferran M, Sagristà M, Olafsson JH, Petersen H, Sigurdsson MI, et al. Streptococcus pyogenes-induced cutaneous lymphocyte antigen-positive T cell-dependent epidermal cell activation triggers TH17 responses in patients with guttate psoriasis. J Allergy Clin Immunol. 2016 Aug; 138(2): 491-499.e6.

67. Yan D, Issa N, Afifi L, Jeon C, Chang HW, Liao W. The Role of the Skin and Gut Microbiome in Psoriatic Disease. Curr Dermatol Rep. 2017 Jun; 6(2): 94-103.

68. Arck P, Handjiski B, Hagen E, Pincus M, Bruenahl C, Bienenstock J, et al. Is there a ,gut-brain-skin axis'? Exp Dermatol. 2010 May; 19(5): 401-5.

69. Varghese R, Rajappa M, Chandrashekar L, Kattimani S, Archana M, Munisamy M, et al. Association among stress, hypocortisolism, systemic inflammation, and disease severity in chronic urticaria. Ann Allergy Asthma Immunol. 2016 Apr; 116(4): 344-348.e1.

70. Lin TK, Zhong L, Santiago JL. Association between Stress and the HPA Axis in the Atopic Dermatitis. Int J Mol Sci. 2017 Oct 12; 18(10). pii: E2131.

71. Vegas O, Poligone B, Blackcloud P, Gilmore ES, VanBuskirk J, Ritchlin $\mathrm{CT}$, et al. Chronic social stress Ameliorates psoriasiform dermatitis through upregulation of the Hypothalamic-Pituitary-Adrenal axis. Brain Behav Immun. 2017 Nov 7. pii: S0889-1591(17)30479-8.

72. Zhang H, Caudle Y, Wheeler C, Zhou Y, Stuart C, Yao B, et al. TGF- $\beta 1 /$ Smad2/3/Foxp3 signaling is required for chronic stressinduced immune suppression. J Neuroimmunol. 2017 Nov 8. pii: S0165-5728(17): 30465-4.

73. Kang Y, Cai Y, Pan W. Change in gut microbiota for eczema: Implications for novel therapeutic strategies. Allergol Immunopathol (Madr). 2017 Dec 23. pii: S0301-0546(17): 30104-0.

74. Carrascosa JM, Vilavella M, Garcia-Doval I, Carretero G, Vanaclocha F, Daudén E, et al. Body mass index in patients with moderate-to-severe psoriasis in Spain and its impact as an independent risk factor for therapy withdrawal: results of the Biobadaderm Registry. J Eur Acad Dermatol Venereol. 2014 Jul; 28(7): 907-14.

75. Barrea L, Nappi F, Di Somma C, Savanelli MC, Falco A, Balato A, et al. Environmental Risk Factors in Psoriasis: The Point of View of the Nutritionist. Int J Environ Res Public Health. 2016 Jul 22; 13(5).

76. Armstrong AW, Harskamp CT, Armstrong EJ. The association between psoriasis and obesity: a systematic review and metaanalysis of observational studies. Nutr Diabetes. 2012 Dec 3; 2: e54.

77. Fleming P, Kraft J, Gulliver WP, Lynde C. The relationship of obesity with the severity of psoriasis: A systematic review. J. Cutan. Med. Surg. 2015; 19: 450-456.

78. Naldi L, Conti A, Cazzaniga S, Patrizi A, Pazzaglia M, Lanzoni A, et al. Diet and physical exercise in psoriasis: a randomized controlled trial. Br J Dermatol. 2014 Mar; 170(3): 634-42.

79. Voiculescu VM, Lupu M, Papagheorghe L, Giurcaneanu C, Micu E. Psoriasis and metabolic syndrome-Scientific evidence and therapeutic implications. J Med Life 2014; 7: 468-471.

80. Correia B, Torres T. Obesity: a key component of psoriasis. Acta Biomed. 2015 Sep 14; 86(2): 121-9.

81. Carrascosa JM, Rocamora V, Fernandez-Torres RM, Jimenez-Puya R, Moreno JC, Coll-Puigserver N, et al. Obesity and psoriasis: 
Inflammatory nature of obesity, relationship between psoriasis and obesity, and therapeutic implications. Actas Dermosifiliogr. 2014 Jan-Feb; 105(1): 31-44.

82. Xu H, Barnes GT, Yang Q, Tan G, Yang D, Chou CJ, et al. Chronic inflammation in fat plays a crucial role in the development of obesityrelated insulin resistance. J Clin Invest. 2003; 112: 1821-30.

83. La Cava A, Alviggi C, Matarese G. Unraveling the multiple roles of leptin in inflammation and autoimmunity. J Mol Med. 2004; 82: 4-11.

84. Conde, J, Scotece M, Gomez R, López V, Gómez-Reino JJ, Lago F, et al. Adipokines: biofactors from white adipose tissue. A complex hub among inflammation, metabolism, and immunity. Biofactors. 2011 Nov-Dec; 37(6): 413-20.

85. Zhu KJ, Zhang C, Li M, Zhu CY, Shi G, Fan YM. Leptin levels in patients with psoriasis: A meta-analysis. Clin Exp Dermatol. 2013; 38: 478-483.

86. Chen YJ, Wu CY, Shen JL, Chu SY, Chen CK, Chang YT, et al. Psoriasis independently associated with hyper leptinemia contributing to metabolic syndrome. Arch Dermatol. 2008; 144(12): 1571-5.

87. Peluso I, Palmery M. The relationship between body weight and inflammation: Lesson from anti-TNF- antibody therapy. Hum Immunol. 2016 Jan; 77(1): 47-53.

88. Hamminga EA, van der Lely AJ, Neumann HA, Thio HB. Chronic inflammation in psoriasis and obesity: implications for therapy. Med Hypotheses. 2006; 67(4): 768-73.

89. Al-Mutairi N, Nour T. The effect of weight reduction on treatment outcomes in obese patients with psoriasis on biologic therapy: A randomized controlled prospective trial. Expert Opin Biol Ther. 2014 Jun; 14(6): 749-56.

90. Debbaneh M, Millsop JW, Bhatia BK, Koo J, Liao W. Diet and Psoriasis: Part I. Impact of Weight Loss Interventions. J Am Acad Dermatol. 2014 Jul; 71(1): 133-40.

91. Guida, B, Napoleone, A, Trio R, Nastasi A, Balato N, Laccetti R, et al. Energy-restricted, n-3 polyunsaturated fatty acids-rich diet improves the clinical response to immuno-modulating drugs in obese patients with plaque-type psoriasis: A randomized control clinical trial. Clin Nutr. 2014 Jun; 33(3): 399-405.

92. Millsop JW, Bhatia BK, Debbaneh M, Koo J, Liao W. Diet and Psoriasis: Part 3. Role of Nutritional Supplements. J Am Acad Dermatol. 2014 Sep; 71(3): 561-9.

93. Bhatia, Bhavnit K. Koo J, Linos E, Liao W. Diet and Psoriasis: Part 2. Celiac Disease and Role of a Gluten-Free Diet. J Am Acad Dermatol. 2014 Aug; 71(2): 350-8.

94. Murzaku EC, Bronsnick T, Rao B.K. Diet in dermatology: Part II. Melanoma, chronic urticaria, and psoriasis. J Am Acad Dermatol. 2014; 71: 1053.e1-1053.e16.

95. Salas-Salvadó J, Guasch-Ferré M, Lee CH, Estruch R, Clish CB, Ros E. Protective effects of the mediterranean diet on type 2 diabetes and metabolic syndrome. J Nutr. 2016; 146: S920-S927.

96. Esposito K, Giugliano D. Mediterranean diet for primary prevention of cardiovascular disease. N Engl J Med. 2013; 369: 674-675.

97. Esposito K, Di Palo C, Maiorino MI, Petrizzo M, Bellastella G, Siniscalchi I, et al. Long-term effect of mediterranean-style diet and calorie restriction on biomarkers of longevity and oxidative stress in overweight men. Cardiol Res Pract. 2010 Dec 20; 2011: 293916.

98. Armstrong AW, Harskamp CT, Dhillon JS, Armstrong EJ. Psoriasis and smoking: a systematic review and meta-analysis. Br J Dermatol. 2014 Feb; 170(2): 304-14.

99. Zhu KJ, He SM, Sun LD, Hu D, Cheng H, Zhang Z, et al. Smoking and psoriasis: a meta-analysis of case-control studies. J Dermatol Sci. 2011 Aug; 63(2): 126-8.
100. Yanbaeva DG, Dentener MA, Creutzberg EC, Wesseling G, Wouters EF. Systemic effects of smoking.Chest. 2007 May; 131(5): 1557-66.

101. Armstrong AW, Armstrong EJ, Fuller EN, Sockolov ME, Voyles SV. Smoking and pathogenesis of psoriasis: a review of oxidative, inflammatory and genetic mechanisms. Br J Dermatol. 2011; 165: $1162-8$.

102. Emre S, Metin A, Demirseren DD, Kilic S, Isikoglu S, Erel O. The relationship between oxidative stress, smoking and the clinical severity of psoriasis. J Eur Acad Dermatol Venereol. 2012; 27: e370-5.

103. Hojgaard P, Glintborg B, Hetland ML, Hansen TH, Lage-Hansen PR, Petersen $\mathrm{MH}$, et al. Association between tobacco smoking and response to tumour necrosis factor alphainhibitor treatment in psoriatic arthritis: results from the DANBIO registry. Ann Rheum Dis. 2015; 74: 2130-2136.

104. Farkas A, Kemeny L. Alcohol, liver, systemic inflammation and skin: a focus on patients with psoriasis. Skin Pharmacol Physiol. 2013; 26(3): 119-26.

105. Weatherhead SC, Farr PM, Reynolds NJ. Spectral effects of UV on psoriasis. Photochem Photobiol Sci. 2013; 12: 47-53.

106. Wolf P, Weger W, Patra V, et al. Desired response to phototherapy versus photo-aggravation in psoriasis: what makes the difference? Exp Dermatol. 2016; 25: 937-944.

107. De Gruijl FR. For better or for worse, UV in psoriasis. Exp Dermatol. 2016; 25: 945-946.

108. Rutter KJ, Watson RE, Cotterell LF, et al. Severely photosensitive psoriasis: a phenotypically defined patient subset. J Invest Dermatol. 2009 Dec; 129(12): 2861-7.

109. Ros AM, Eklund G. Photosensitive psoriasis. An epidemiologic study. J Am Acad Dermatol. 1987 Nov; 17(5 Pt 1): 752-8.

110. Balak DM1, Hajdarbegovic E Drug-induced psoriasis: clinical perspectives. Psoriasis (Auckl). 2017 Dec 7; 7: 87-94. doi: 10.2147/ PTT.S126727. eCollection 2017.

111. Kim GK, Del RJ. Drug-provoked psoriasis: is it drug induced or drug aggravated? understanding pathophysiology and clinical relevance. J Clin Aesthet Dermatol. 2010; 3: 32-38.

112. Abel EA, DiCicco LM, Orenberg EK, Fraki JE, Farber EM. Drugs in exacerbation of psoriasis. J Am Acad Dermatol. 1986; 15(5 pt 1).

113. Mrowietz U, Domm S. Systemic steroids in the treatment of psoriasis: what is fact, what is fiction? J Eur Acad Dermatol Venereol. 2013; 27(8): 1022-1025.

114. Ishii-Osai Y, Yoneta A, Mizugaki N, Takahashi H, Yamashita T, et al. Infliximab treatmentinduced paradoxical psoriasiform reaction in patient with psoriasis vulgaris showing positive lymphocyte transportation test reaction. JAAD Case Rep. 2015 Jul 1; 1(4): 230-3.

115. Biljan D, Laufer D, Filaković P, Situm M, Brataljenović T. Psoriasis, mental disorders and stress. Coll Antropol. 2009; 33: 889-92.

116. Baker BS, Powles A, Fry L. Peptidoglycan: a major aetiological factor for psoriasis? Trends Immunol. 2006; 27: 545-551.

117. Park BS, Youn JI. Factors influencing psoriasis: an analysis based upon the extent of involvement and clinical type. J Dermatol. 1998; 25: 97-102.

118. Brufau RM, Brufau RS, Gorgojo MA, et al. Psoriasis lesions are associated with specific types of emotions. Emotional profile in psoriasis. Eur J Dermatol. 2015 Jul-Aug; 25(4): 329-34.

119. Brufau RM, Berna JC, Redondo CB, et al. Personality styles in patients with psoriasis. Anales de Psicologia, 2010; 26: 335-340.

120. Palijan TZ, Kovacević D, Koić E, et al. The impact of psoriasis on the quality of life and psychological characteristics of persons suffering from psoriasis. Coll Antropol. 2011 Sep; 35 Suppl 2: 81-5. 